\title{
Anthocyanin Profile and Antioxidant Activity of Edible Leaves of Dissotis brazzae Cogn (Melastomataceae)
}

\author{
Christopher Adaku 1, 2, *, Irene Skaar ${ }^{3}$, Hannington Gumisiriza ${ }^{1}$, Robert Byamukama ${ }^{2}$, \\ Monica Jordheim ${ }^{3}$, Oyvind Moksheim Andersen ${ }^{3}$ \\ ${ }^{1}$ Department of Chemistry, Mbarara University of Science and Technology, Mbarara, Uganda \\ ${ }^{2}$ Department of Chemistry, Makerere University, Kampala, Uganda \\ ${ }^{3}$ Department of Chemistry, University of Bergen, Bergen, Norway \\ Email address: \\ adaku09@gmail.com (C. Adaku) \\ ${ }^{*}$ Corresponding author
}

\section{To cite this article:}

Christopher Adaku, Irene Skaar, Hannington Gumisiriza, Robert Byamukama Monica Jordheim, Oyvind Moksheim Andersen. Anthocyanin Profile and Antioxidant Activity of Edible Leaves of Dissotis brazzae Cogn (Melastomataceae). Journal of Food and Nutrition Sciences. Vol. 8, No. 6, 2020, pp. 139-145. doi: 10.11648/j.jfns.20200806.11

Received: November 10, 2020; Accepted: November 20, 2020; Published: November 27, 2020

\begin{abstract}
Anthocyanins are colored bioactive phytochemicals in the class of flavonoids with high potential as dietary antioxidants. Demand for anthocyanins in functional food and nutraceutical industries has continued to increase over the past decades. However, sources of anthocyanins for commercial exploitation are currently limited. Tropical Africa and Uganda in particular, harbors many plant species with potential to serve as new sources of anthocyanins. In this study, the anthocyanin profile and antioxidant activity of edible leaves of Dissotis brazzae, a plant of tropical African origin, were investigated. Two known anthocyanins, (1) cyanidin 3-O- $\beta$-glucopyranoside $(1.28 \pm 0.44 \mathrm{mg} / \mathrm{g}$ fr. wt.) and (2) cyanidin 3-O- $\alpha$-rhamnopyranoside $(1.89 \pm 0.42 \mathrm{mg} / \mathrm{g}$ fr. wt.), were isolated from $D$. brazzae purple leaves by a combination of chromatographic techniques. Their structures were elucidated mainly by homo- and heteronuclear NMR spectroscopy and online HPLC/UV-Vis spectroscopy. The isolated anthocyanins showed appreciable level of antioxidant activity against DPPH, with 1 (IC50=9.2 $\pm 0.2 \mu \mathrm{g} / \mathrm{ml}) \mathrm{showing}$ slightly higher antioxidant potency than $2(\mathrm{IC} 50=14.0 \pm 0.6 \mu \mathrm{g} / \mathrm{ml})$. However, quercetin $(\mathrm{IC} 50=4.5 \pm 0.4 \mu \mathrm{g} / \mathrm{ml}) \mathrm{used}$ as a reference showed a higher antioxidant activity than 1 and 2 . The total anthocyanin content of $D$. brazzae leaves $(317 \mathrm{mg} / 100 \mathrm{~g})$ was within the range $(80-680 \mathrm{mg} / 100 \mathrm{~g})$ of anthocyanins content in most dietary sources. This is the first report of fully characterised anthocyanins from the genus Dissotis, which may be of taxonomic importance. A new dietary source of the rare cyanidin 3-O- $\alpha$-rhamnopyranoside has been identified.
\end{abstract}

Keywords: Dissotis brazzae, Anthocyanins, Nutraceutical, Colorant, Dietary Antioxidant, Functional Food

\section{Introduction}

Day by day anthocyanins are increasingly becoming popular phytochemicals because of their safety and potential applications in functional food, nutraceutical, cosmetic, pharmaceutical and flower industries [1-3]. Anthocyanins are a class of flavonoids responsible for most of the red to blue colors exhibited by the various plant parts. They exist in a diversity of structures which impart characteristic properties including color hue, intensity, bioactivity and metabolism pathway [4]. The biological activity of anthocyanins may be attributed to their antioxidant potency which is also structure dependent [5]. Distribution of anthocyanins in plants varies with genotype, cultivar, geographical location, agricultural practices and climatic conditions [6, 7]. Therefore, in order to utilise plant sources of anthocyanins as food colorant, functional food as well as nutraceutical, chemical characterisation of the anthocyanin extracts has been recommended [8]. Currently, plants are the main source of anthocyanins for commercial application. However, the available plant sources have so far failed to meet the increasing demand for commercial diversity of anthocyanins. 
More so, advances in technology such as cell culture and genetic engineering in anthocyanin production have also at the moment failed to produce commercial amounts of anthocyanins [9-11]. This therefore calls for a search for more plant sources of anthocyanins.

Many plants of African origin have not been adequately investigated with regard to anthocyanins. In our effort to unearth new sources of anthocyanins for food colorant, functional food and nutraceutical application from tropical African plants, Dissotis brazzae was investigated. D. brazzae is a native plant of the tropical region of Africa ranging from Guinea Republic to Angola, Democratic Republic of Congo, Uganda, Kenya and Tanzania [12]. It belongs to Melastomataceae family and the genus Dissotis is comprised of 140 species [13]. It is regarded as an important wild plant due to its medicinal and food value. In Western Uganda, the leaves are consumed as snacks by mainly herdsmen and children. In Democratic Republic of Congo, the plant is used as a medicinal herb against sickle cell [14]. The Hayas of the Kagera region in Tanzania use the plant to manage syphilis and cerebral malaria [15]. The leaf decoction has an anesthetic effect and is drunk to induce sleep and as an anthelmintic [16]. There are also reports of antimicrobial activity and antiplasmodial activity of $D$. brazzae leaves [15].

In spite of the seemingly popular ethnomedical and food utilisation of $D$. brazzae, its phytochemistry remains largely unknown. Generally, information on the phytochemical composition of the genus Dissotis is lacking. Out of the 140 species, only Dissotis rotundifolia and Dissotis erecta have been partly investigated for their phytochemical composition. The presence of alkaloids, tannins, saponins, flavonoids, anthraquinone, anthocyanin, terpenoids, phenols and cardiac glycosides in the leaves of $D$. rotundifolia has been reported $[17,18]$. In addition, kaempferol-3-O- $\beta$-D-glucopyranose and kaempferol from $D$. erecta and apigenin-8-C- $\beta$-D-glucopyranoside and luteolin- $8-C-\beta-D-$ glucopyranose from $D$. rotundifolia were identified by [19]. However, to the best of our knowledge the characterisation of anthocyanins from the Dissotis genus has not been reported before. In this paper, we report the anthocyanin profile and antioxidant activity of the mature purple leaves of $D$. brazzae.

\section{Materials and Methods}

\subsection{Isolation of Anthocyanins}

Fresh purple leaves of $D$. brazzae were collected from the bushes in Kyeizooba Sub-county, Bushenyi district, Uganda (approximate coordinates: $00^{\circ} 36^{\prime} 46.2^{\prime \prime} \mathrm{S}, 30^{\circ} 15^{\prime} 35.7^{\prime \prime} \mathrm{E}$ ) in June, 2014. The plant was identified at the Herbarium of Botany Department, Makerere University where a voucher specimen (Adaku No. 03) was deposited. The fresh leaves (536 g) were extracted with $2 \mathrm{~L}$ of methanol containing $0.5 \% \quad(\mathrm{v} / \mathrm{v})$ trifluoroacetic acid (TFA) (Merck, Darmstadt, Germany) in a deep freezer at $4^{\circ} \mathrm{C}$ for 20 hours. The filtered extract was concentrated under reduced pressure at $28^{\circ} \mathrm{C}$ in order to remove the methanol. The concentrate was defatted by partition against ethlyacetate (x2) and afterwards concentrated under reduced pressure to remove traces of the solvent. The unwanted polar compounds were removed by applying the extract to an Amberlite XAD-7 column ( 70 x $5 \mathrm{~cm}$, Sigma-Aldrich, Steinheim, Germany). The anthocyanins adsorbed on the column were washed with water and eluted with methanol containing $0.5 \%$ TFA. The anthocyanins in the concentrated eluate from Amberlite column were separated on Sephadex LH-20 column (10 x $80 \mathrm{~cm}$, Amersham Biosciences, Uppsala, Sweden) using $\mathrm{H}_{2} \mathrm{O} / \mathrm{MeOH} / \mathrm{TFA}(79.5: 20: 0.5, \mathrm{v} / \mathrm{v} / \mathrm{v})$ solvent with a flow rate of $5 \mathrm{~mL} / \mathrm{min}$. The Sephadex LH-20 fractions with similar qualitative anthocyanin contents (revealed by analytical HPLC) were combined and further purified by preparative reverse-phase HPLC to yield two compounds (1 and 2).

\subsection{Preparative HPLC}

The preparative HPLC system consisted of a Gilson 321 pump and an UltiMate 3000 variable wave length UV detector (Dionex Corporation, Sunnyvale, CA, US), equipped with a $25 \times 2.2 \mathrm{~cm}(10 \mu \mathrm{m})$ Econosphere $\mathrm{C} 18$ column (Grace, Deerfield, IL) and solvents (A) water (0.5\% TFA, v/v) and (B) acetonitrile $(0.5 \% \mathrm{TFA}, \mathrm{v} / \mathrm{v})$. The elution profile consisted of initial conditions with $90 \% \mathrm{~A}$ and $10 \% \mathrm{~B}$ followed by a linear gradient elution for the next $10 \mathrm{~min}$ to $14 \% \mathrm{~B}$, isocratic elution (10-14 $\mathrm{min})$, and the subsequent linear gradient conditions: $14-18 \mathrm{~min}$ (to $16 \% \mathrm{~B}$ ), $18-22 \mathrm{~min}$ (to $18 \% \mathrm{~B}$ ), $22-26 \mathrm{~min}$ (to $23 \% \mathrm{~B}$ ), $26-31 \mathrm{~min}$ (to $28 \% \mathrm{~B}$ ), and $31-32 \mathrm{~min}$ (to $40 \% \mathrm{~B}$ ), with isocratic elution at $32-40 \mathrm{~min}$ (to $40 \% \mathrm{~B}$ ) and a final linear gradient elution at $43-46 \mathrm{~min}$ (to $10 \% \mathrm{~B}$ ). The flow rate was $15 \mathrm{~mL} / \mathrm{min}$, and aliquots of $250 \mu \mathrm{L}$ were injected manually. Prior to injection, all samples were filtered through a $0.45 \mu \mathrm{m}$ Millipore membrane filter.

\subsection{Analytical HPLC}

Analytical HPLC was performed using Agilent 1100 HPLC system (Agilent Technologies, Santa Clara, CA, USA) equipped with a HP 1050 diode array detector (Hewlett-Packard), an ODS-Hypersil column $(20 \times 0.5 \mathrm{~cm}$, i.d., $5 \mu \mathrm{m}$; Supelco, Bellefonte, PA, USA), two solvents; A (water/0.5\% TFA; v/v) and B (acetonitrile/0.5\% TFA; v/v). The elution profile consisted of initial conditions with $90 \%$ A and $10 \% \mathrm{~B}$ followed by a linear gradient elution for the next $10 \mathrm{~min}$ to $14 \% \mathrm{~B}$, isocratic elution (10-14 $\mathrm{min})$, and then subsequent linear gradient conditions; $14-18 \mathrm{~min}$ (to $16 \% \mathrm{~B}$ ), $18-22 \mathrm{~min}$ (to $18 \% \mathrm{~B}$ ), $22-26 \mathrm{~min}$ (to $23 \% \mathrm{~B}$ ), $26-31 \mathrm{~min}$ (to $28 \% \mathrm{~B}$ ), and $31-32 \mathrm{~min}$ (to $40 \% \mathrm{~B}$ ), isocratic elution $32-40 \mathrm{~min}$ $(40 \% \mathrm{~B})$, and final linear gradient elution $43-46 \mathrm{~min}$ (to $10 \% \mathrm{~B}$ ). The flow rate was $1.0 \mathrm{~mL} / \mathrm{min}$, and aliquots of $15 \mu \mathrm{L}$ were injected with an Agilent 1100 Series microautosampler. Prior to injection, all samples were filtered through a $0.45 \mu \mathrm{m}$ Millipore membrane filter. The UV-Vis absorption spectra were recorded online during HPLC analysis over the wavelength range of $240-600 \mathrm{~nm}$ in steps of $2 \mathrm{~nm}$.

\subsection{NMR Spectroscopy}

The NMR spectra were obtained at $600.13 \mathrm{MHz}\left({ }^{1} \mathrm{H}\right)$ and 
150.92 MHz $\left({ }^{13} \mathrm{C}\right)$ on a Bruker Biospin Ultrashield Plus AV-600 $\mathrm{MHz}$ instrument equipped with a TCI ${ }^{1} \mathrm{H}^{-13} \mathrm{C} /{ }^{15} \mathrm{~N}$ CryoProbe head (Bruker BioSpin, Zürich, Switzerland). All spectra were recorded at $298 \mathrm{~K}$ and the deuteriomethyl ${ }^{13} \mathrm{C}$ signal and the residual ${ }^{1} \mathrm{H}$ signal of the solvent $\left(\mathrm{CF}_{3} \mathrm{COOD}-\mathrm{CD}_{3} \mathrm{OD} ; 5: 95, \mathrm{v} / \mathrm{v}\right)$ were used as secondary references ( $\delta 49.0$ and 3.40 from TMS, for ${ }^{1} \mathrm{H}$ and ${ }^{13} \mathrm{C}$, respectively) [20]. The NMR experiments ${ }^{1} \mathrm{H}$, ${ }^{1} \mathrm{H}-{ }^{13} \mathrm{C}$ HSQC, ${ }^{1} \mathrm{H}-{ }^{13} \mathrm{C}$ HMBC, ${ }^{1} \mathrm{H}-{ }^{1} \mathrm{H}$ DQF-COSY and ${ }^{1} \mathrm{H}-{ }^{1} \mathrm{H}$ TOCSY were recorded.

\subsection{Quantitative Determination of Anthocyanins}

HPLC method was used to determine the amounts of the individual anthocyanins as described by [21]. Briefly, fresh purple leaves of D. brazzea $(10 \mathrm{~g})$ was extracted for 15 hours in $20 \mathrm{~mL}$ of methanol containing $0.5 \% \mathrm{TFA}(\mathrm{v} / \mathrm{v})$ in a refrigerator. The extraction was repeated twice to exhaust the pigments and the combined extracts were transferred into a volumetric flask to determine the total volume. The quantitative amounts of anthocyanins 1 and 2 were determined from a HPLC calibration curve based on pure cyanidin 3-glucoside $(>95 \%$, determined by HPLC-DAD/NMR standardization) isolated from wild Norwegian blackberries, without taking into account the variation of molar absorption coefficients for individual pigments. Five replicates of the sample were analysed. The results were presented as milligrams of cyanidin 3-glucoside equivalents per $100 \mathrm{~g}$ of fresh weight.

\subsection{Antioxidant Assay}

The free radical scavenging activity of the extract was determined according to the method described by [22]. Briefly, solutions of 1, 1-Diphenyl-2-picrylhydrazyl (DPPH) in methanol $(4 \mathrm{mg} / \mathrm{ml})$ and the test compound in DMSO (10 $\mathrm{mg} / \mathrm{ml})$ were prepared. UV absorbance at $517 \mathrm{~nm}\left(A_{517}=1.0\right)$ for an aliquot of the DPPH solution $(2.95 \mathrm{ml})$ was measured. The aliquot was mixed with the test compound solution $(0.05$ $\mathrm{ml}$ ) and the UV absorbance at $517 \mathrm{~nm}$ was measured for $5 \mathrm{~min}$. The procedure was repeated for the test compound serial dilutions of 5, 2.5, 1.3, $0.7 \mathrm{mg} / \mathrm{ml}$. Quercetin was used as a positive control. All aliquots were analyzed in triplicate and results given as averages \pm standard deviation.

\section{Results and Discussion}

\subsection{Structure Determination}

\subsubsection{HPLC and On-line UV-Visible Analysis}

The HPLC profile (Figure 1a) of D. brazzea purple leaves extract detected at $520 \pm 20 \mathrm{~nm}$ revealed two major anthocyanins (1\&2). The On-line UV-Visible spectra (Figure 1b) showed that both anthocyanins absorb at the same wavelength in the visible region $\left(\lambda_{V_{\text {is-max }}}\right.$ at $\left.516 \mathrm{~nm}\right)$, which points to an aglycone with two oxygen-functions on the B-ring (cyanidin or peonidin) [23]. From table 1 , the $\mathrm{A}_{440} / \mathrm{A}_{V_{\mathrm{Vis}} \max }$ of $31.8 \%$ for 1 and $32.3 \%$ for 2 were in accordance with 3-glycosyl substitution and the $\mathrm{A}_{\mathrm{UV} \text {-max }} / \mathrm{A}_{\mathrm{Vis-max}}$ of 0.54 for each pigment indicated one sugar moiety [24]. The absence of local $\lambda_{\max }$ around $310-330 \mathrm{~nm}$ in the UV region of the spectra showed absence of aromatic acylation [25]. Thus, compounds 1 and 2 were deemed to be 3-monoglycosides of cyanidin or peonidin.

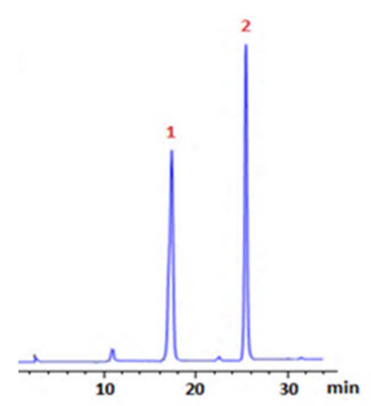

(a)

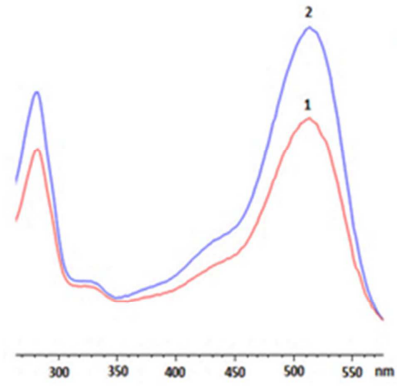

(b)
Figure 1. (a) HPLC profile for anthocyanins 1 and 2 (b) On-line UV-Visible spectra for anthocyanins 1 and 2 .

Table 1. UV-Vis data for anthocyanins 1 and 2.

\begin{tabular}{lllll}
\hline Compound & $\boldsymbol{\lambda}_{\text {Vis max }}$ & $\boldsymbol{\lambda}_{\text {UV max }}$ & $\mathbf{A}_{\mathbf{4 4 0}} / \mathbf{A}_{\text {vis max }}$ & $\mathbf{A}_{\text {UV-max }} / \mathbf{A}_{\text {Vis-max }}$ \\
\hline Anthocyanin 1 & 516 & 280 & 31.8 & 0.54 \\
Anthocyanin 2 & 516 & 280 & 32.3 & 0.54 \\
\hline
\end{tabular}

\subsubsection{NMR Spectroscopy Analysis}

The 1D ${ }^{1} \mathrm{H}$ NMR spectrum of compound 1 showed six signals in the aromatic region. The signals at $\delta 8.14(\mathrm{~d}, \mathrm{~J}=2.3$ $\left.\mathrm{Hz}, \mathrm{H}-2^{\prime}\right), \delta 8.35$ (dd, J=2.3, $\left.8.7 \mathrm{~Hz}, \mathrm{H}-6^{\prime}\right)$ and $\delta 7.11(\mathrm{~d}, \mathrm{~J}=8.7$ $\left.\mathrm{Hz}, \mathrm{H}-5^{\prime}\right)$ arose from AMX-system of the anthocyanidin B-ring, while the signals at $\delta 9.12(\mathrm{~d}, \mathrm{~J}=0.8 \mathrm{~Hz}, \mathrm{H}-4), \delta 6.75(\mathrm{~d}$, $\mathrm{J}=1.9 \mathrm{~Hz}, \mathrm{H}-6)$ and $\delta 6.98(\mathrm{dd}, \mathrm{J}=0.8,1.9 \mathrm{~Hz}, \mathrm{H}-8)$ belonged to the A- and C-rings (Table 2). The chemical shifts for the corresponding carbons of aglycone of compound 1 were assigned from the HSQC spectrum. The chemical shifts for quaternary carbon atoms of the aglycone were assigned from the HMBC spectrum using the procedure reported by [26] The assignment of the chemical shifts were in conformity with a cyanidin aglycone. Peonidin was ruled out because there was no absorption corresponding to the $\mathrm{OCH}_{3}$ group.

The $1 \mathrm{D}{ }^{1} \mathrm{H}$ NMR spectrum of compound 2 showed similar signals in the aromatic region; $\delta 8.01\left(\mathrm{~d}, \mathrm{~J}=2.3 \mathrm{~Hz}, \mathrm{H}-2^{\prime}\right), \delta$ $8.11\left(\mathrm{dd}, \mathrm{J}=2.3,8.6 \mathrm{~Hz}, \mathrm{H}-6^{\prime}\right)$ and $\delta 7.14\left(\mathrm{~d}, \mathrm{~J}=8.6 \mathrm{~Hz}, \mathrm{H}-5^{\prime}\right)$ for AMX-system of the anthocyanidin B-ring and $\delta 9.06(\mathrm{~d}$, $\mathrm{J}=0.8 \mathrm{~Hz}, \mathrm{H}-4), \delta 6.76(\mathrm{~d}, \mathrm{~J}=1.9 \mathrm{~Hz}, \mathrm{H}-6)$ and $\delta 6.98(\mathrm{dd}, \mathrm{J}=0.8$, $1.9 \mathrm{~Hz}, \mathrm{H}-8$ ) for A- and C-rings (Table 3 ), also in accordance with cyanidin aglycone.

The TOCSY spectrum of compound 1 revealed one sugar unit. The protons of the sugar unit were assigned from cross-peaks in the DQF-COSY spectrum supported by cross-peaks in the HSQC spectrum [26]. Starting from the anomeric proton at $\delta 5.38$ the observed cross-peak at $\delta$ $5.38 / 3.76$ permitted the assignment of $\delta 3.76$ to $2-\mathrm{H}^{\prime \prime}$. A sequential walk through approach was afterwards used to assign the coupled protons, $3-\mathrm{H}^{\prime \prime}, \delta 3.63$ (3.76/3.63), 4- $\mathrm{H}^{\prime \prime}, \delta$ 3.53 (3.63/3.53), 5- $\mathrm{H}^{\prime \prime}, \delta 3.65(3.53 / 3.65), 6 \mathrm{~B}-\mathrm{H}^{\prime \prime}, \delta 3.80$ $(3.65 / 3.80)$ and $6 \mathrm{~A}-\mathrm{H}^{\prime \prime}, \delta 4.00(3.65 / 3.80 / 4.00)$ (Table 2). The corresponding sugar carbons were assigned from their cross-peaks in the HSQC spectrum. The range of chemical shift values from $\delta 62.4$ to $\delta 78.7$ of the non-anomeric carbons 
was indicative of a pyranose hexose [27]. The chemical shifts and coupling constants were in conformity with a $\beta$-glucopyranoside. A cross-peak at $\delta .38 / 145.5(\mathrm{H}-1 " / \mathrm{C}-3)$ in the HMBC spectrum confirmed the linkage of the glucopyranose moiety to the 3 - position of the aglycone while the coupling constant of the anomeric proton at $\delta 5.38(\mathrm{~d}$, $\left.\mathrm{J}=7.8 \mathrm{~Hz}, 1-\mathrm{H}^{\prime \prime}\right)$ confirmed the $\beta$-configuration. Therefore, compound 1 was identified as cyanidin-3-O- $\beta$-glucopyranoside (Figure 2 (a))

From the TOCSY spectrum of compound 2, only one sugar unit was also revealed and it was observed that one of the proton signals of this sugar unit was at high-field, $\delta 1.37(\mathrm{~d}$, $\mathrm{J}=6.1 \mathrm{~Hz}$ ). This signal is typically associated with a rhamnose moiety [28]. The chemical shifts and the ${ }^{1} \mathrm{H}-{ }^{1} \mathrm{H}$ coupling constants for the sugar moiety were established from the DQF-COSY and the HSQC spectra (Table 3), confirming the rhamnopyranosyl group. A cross-peak at $\delta$ 5.84/145.7 $\left(1-\mathrm{H}^{\prime \prime} / \mathrm{C}-3\right)$ in the HMBC spectrum confirmed the linkage of the rhamnopyranosyl group to the 3-position of the aglycone while the coupling constant of the anomeric proton at $\delta 5.84(\mathrm{~d}$, $\left.\mathrm{J}=1.7 \mathrm{~Hz}, 1-\mathrm{H}^{\prime \prime}\right)$ confirmed the $\alpha$-configuration. Therefore, compound 2 was identified as cyanidin-3-O- $\alpha$-rhamnopyranoside (Figure 2 (b)).

Table 2. Proton and Carbon-13 NMR spectral data for anthocyanin $\mathbf{1}$ (cyanidin-3-O- $\beta$-glucopyranoside).

\begin{tabular}{lll}
\hline & ${ }^{1} \mathbf{H} \boldsymbol{\delta}(\mathbf{p p m})$, multiplicity, $\boldsymbol{J}(\mathbf{H Z})$ & ${ }^{13} \mathbf{C} \boldsymbol{\delta}(\mathbf{p p m})$ \\
\hline Aglycone & & \\
2 & & 164.3 \\
3 & & 145.5 \\
4 & $9.02, d 0.9$ & 136.9 \\
5 & & 159.0 \\
6 & $6.75, d 1.9$ & 103.3 \\
7 & & 170.3 \\
8 & $6.98, d d 0.8,1.9$ & 95.1 \\
9 & & 157.6 \\
10 & & 113.2 \\
$1^{\prime}$ & & 121.1 \\
$2^{\prime}$ & $8.14, d 2.3$ & 118.4 \\
$3^{\prime}$ & & 147.3 \\
$4^{\prime}$ & & 155.7 \\
$5^{\prime}$ & $7.11, d 8.7$ & 117.4 \\
$6^{\prime}$ & $8.32, d d 2.3,8.7$ & 128.2 \\
$3-O-\beta$ - glucopyranosyl & & \\
$1^{\prime \prime}$ & $5.38, d 7.8$ & 103.7 \\
$2^{\prime \prime}$ & $3.76, d d 7.8,9.3$ & 74.8 \\
$3^{\prime \prime}$ & $3.68, t 9.3$ & 78.2 \\
$4^{\prime \prime}$ & $3.57, d d 9.1,9.7$ & 71.1 \\
$5^{\prime \prime}$ & $3.65, d d d 2.3,6.0,9.7$ & 78.7 \\
6 A" & $4.00, d d 2.2,12.1$ & 62.4 \\
$6 B^{\prime \prime}$ & $3.80, d d 6.0,12.1$ & 62.4 \\
\hline
\end{tabular}

$\mathrm{s}=$ singlet, $\mathrm{d}=$ doublet, $\mathrm{t}=$ triplet, $\mathrm{dd}=$ double doublet, $\mathrm{ddd}=$ double double doublet

Table 3. Proton and Carbon-13 NMR spectral data for anthocyanin 2 (cyanidin-3-O- $\alpha$-rhamnopyranoside).

\begin{tabular}{lll}
\hline & ${ }^{1} \mathbf{H} \boldsymbol{\delta}(\mathbf{p p m})$, multiplicity, $\boldsymbol{J}(\mathbf{H Z})$ & ${ }^{13} \mathbf{C} \boldsymbol{\delta}(\mathbf{p p m})$ \\
\hline Aglycone & \\
2 & & 164.4 \\
3 & & 145.7 \\
4 & $9.06, d 0.8$ & 136.6 \\
5 & & 158.6 \\
\hline
\end{tabular}

\begin{tabular}{lll}
\hline & ${ }^{1} \mathbf{H} \boldsymbol{\delta}(\mathbf{p p m})$, multiplicity, $\boldsymbol{J}(\mathbf{H Z})$ & ${ }^{13} \mathbf{C} \boldsymbol{\delta}(\mathbf{p p m})$ \\
\hline 6 & $6.76, d 1.9$ & 103.4 \\
7 & & 170.3 \\
8 & $6.98, d d 0.8,1.9$ & 95.1 \\
9 & & 157.8 \\
10 & & 113.3 \\
$1^{\prime}$ & & 121.2 \\
$2^{\prime}$ & $8.01, d 2.3$ & 118.1 \\
$3^{\prime}$ & & 147.6 \\
4 & & 155.5 \\
$5^{\prime}$ & $7.14, d 8.6$ & 117.4 \\
$6^{\prime}$ & $8.11, d d 2.3,8.6$ & 127.3 \\
$3-O-\alpha-$ rhamnopyranosyl & & \\
$1^{\prime \prime}$ & $5.84, d 1.7$ & 102.5 \\
$2^{\prime \prime}$ & $4.31, d d 1.8,3.4$ & 71.6 \\
$3^{\prime \prime}$ & $4.01, d d 3.4,9.3$ & 72.3 \\
$4^{\prime \prime}$ & $3.65, t 9.4$ & 73.3 \\
$5^{\prime \prime}$ & $3.72, d d 6.2,9.5$ & 72.2 \\
$6 A^{\prime \prime}$ & $1.37, d 6.1$ & 17.9 \\
$6 B^{\prime \prime}$ & & \\
\hline
\end{tabular}

$\mathrm{s}=$ singlet, $\mathrm{d}=$ doublet, $\mathrm{t}=$ triplet, $\mathrm{dd}=$ double doublet, $\mathrm{ddd}=$ double double doublet

Of the two anthocyanins isolated from $D$. brazzae leaves, cyanidin-3-glucoside is the most common anthocyanin found in plants, with $50 \%$ distribution in fruits and vegetables $[29,1]$. Previously, this pigment was reported to occur in Melastomataceae family in the flowers of Melastoma sanguineurn Sims and Oritrephes grandijlora Ridl [30]. Cyanidin-3-glucoside may be regarded as an important phytochemical due to its beneficial effects on human health. Studies have revealed that cyanidin-3-glucoside exhibits chemopreventive and chemotherapeutic activity in cultured JB6 cells, suggesting that this pigment may function as a prospective anticancer agent [31].

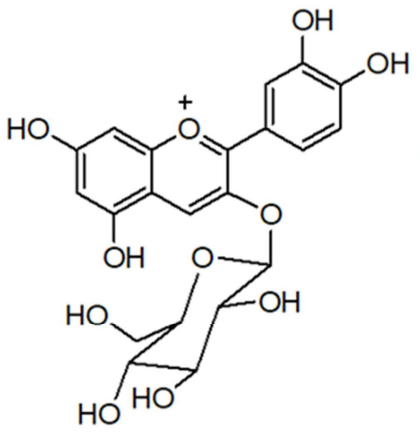

(a)<smiles>CC(O)C1OC(Oc2cc3c(O)cc(O)cc3[o+]c2-c2ccc(O)c(O)c2)C(O)C(O)C(O)C1C</smiles>

(b)
Figure 2. (a) Structure of cyanidin-3-O- $\beta$-glucopyranoside (b) Structure of cyanidin-3-O- $\alpha$-rhamnopyranoside.

On the contrary, the occurrence of cyanidin 3-rhamnoside is quite rare and we have not found any report of its occurrence in Melastomataceae family. It has so far been isolated from few plants including taro (Colocasia esculenta (L.)) corms [32], phosphorous-deficient leaves of maize (Zeamays Var. Ganga-5) [33], flowers of Salvia splendes Var. Amethyst [34], acerola (Malpighia emarginata DC) fruits [35] and buckwheat (Fagopyrum esculentum Moench) flowers [36]. This distribution clearly shows that cyanidin 3-rhamnoside has not been previously identified in the leaves that are produced 
under natural conditions. The distribution also shows that the pigment is not readily available in the human diet, appearing only as a minor component in acerola fruits. Therefore, to the best of our knowledge this is the first time cyanidin 3-rhamnoside is being reported as a major component of human diet. In addition, the occurrence of rhamnose as a monosaccharide moiety in anthocyanins is less common. It mainly occurs as a rutinose disaccharide moiety and other polysaccharides. Owing to the limited availability, the functional properties of cyanidin 3-rhamnoside have not been extensively studied. However, [35] reported that cyanidin 3-rhamnoside isolated from acerola exhibited strong antioxidant activity and strongly inhibited advanced glycation end products (AGES) which are associated with diabetes mellitus. In another study on effects of anthocyanidins and anthocyanins on drug metabolizing cytochromes P450 in primary human hepatocytes and human liver microsomes, cyanidin 3-rhamnoside together with other anthocyanins did not induce human CYP2A6, CYP2B6, CYP2C9, and CYP3A4. Unfortunately, the anthocyanins inhibited the marker activities of CYP enzymes to a significant extent, with cyanidin 3-rhamnoside exerting the strongest inhibitory effect [37]. However, the low levels of ingestion of anthocyanins as food or dietary supplement will seldom cause an induction or inhibition of CYP.

\subsection{Antioxidant Activity of the Anthocyanins}

The IC50 (the concentration of sample that reduced the initial DPPH concentration by $50 \%$ ) values for D. brazzae anthocyanins (See Table 4) suggest appreciable radical scavenging activity against DPPH, which is consistent with other reports [38, 39]. Generally, the electron deficient structure of anthocyanins earns them natural antioxidant activity which is modulated by their structure. Among the anthocyanins, cyanidin and cyanidin-glycosides have been more widely studied for their antioxidant activity mainly because of their greater distribution in plants. Various in vitro and in vivo studies have reported remarkable antioxidant activity of cyanidin and cyanidin glycosides. In fact, in many instances cyanidin and cyanidin 3-glucoside exhibited higher antioxidant activity than Trolox (Vitamin E analogue) $[38,40]$ and comparable or higher activity than tert-butylhydroquinone and butylated hydroxytoluene [41, 42] which are renown antioxidants. Cyanidin 3-glucoside also showed a significant antioxidant capacity in the protection of human low density lipoprotein (LDL) oxidation, which was superior to both ascorbic acid and resveratrol [43]. According to [44] cyanidin and cyanidin 3-glucoside demonstrated higher antioxidant efficacy than $\alpha$-tocopherol in rat liver microsomes but similar activity as $\alpha$-tocopherol in liposomes and rabbit erythrocyte. More importantly, the antioxidant activity of cyanidin and cyanidin 3-glucoside reduced cytotoxicity and apoptosis without causing toxic side effects on the cell [45, 46]. However, in this study the remarkable antioxidant activity demonstrated by $D$. brazzae anthocyanins was lower than the antioxidant activity of quercetin.

\subsection{Quantification of the Anthocyanins}

The total anthocyanin content of $D$. brazzae leaves was 317 $\mathrm{mg} / 100 \mathrm{~g}$ fresh weight (Table 4). Since leaves are scarce as dietary sources of anthocyanins, most studies on anthocyanins in leaves tend to focus on the qualitative rather than the quantitative content. Therefore, information regarding the quantitative content of anthocyanins in leaves is generally scanty. Many dietary sources contain variable quantitative amounts of anthocyanins due to several factors including stage of maturity, period of harvest, genotype, cultural practices, etc. However, the total anthocyanin content in D. brazzae leaves was within the range $(80-680 \mathrm{mg} / 100 \mathrm{~g})$ of anthocyanins content in some edible fruits [47] and within the range (181.2-716.4 mg/100g) of anthocyanin content in grape varieties [48] which serve as a major commercial source for anthocyanins. This shows that the quantity of anthocyanins in $D$. brazzae leaves is appreciable.

\section{Conclusion}

Anthocyanins have been identified in Dissotis genus for the first time. The revelation of these anthocyanins may be of paramount chemotaxonomic importance. A new source for the uncommon cyanidin 3-rhamnoside has been identified, which may enhance comparative studies of anthocyanins. The appreciable quantity and remarkable antioxidant potency of $D$. brazzae anthocyanins suggest that this plant may serve as a useful source of anthocyanins for dietary antioxidants and nutraceutical and functional food development.

Table 4. Quantitative amounts of anthocyanins 1 and 2 and IC50 for anthocyanins 1 and 2 and Quercetin.

\begin{tabular}{lll}
\hline Compound & Amount $(\mathbf{m g} / \mathbf{1 0 0 g}$ fr. wt) & IC50 \pm S. D. $(\boldsymbol{\mu g} / \mathbf{m l})$ \\
\hline Anthocyanin 1 & $128 \pm 0.44$ & $9.2 \pm 0.2$ \\
Anthocyanin 2 & $189 \pm 0.42$ & $14.0 \pm 0.6$ \\
Anthocyanins 1 \& 2 & $317 \pm 0.43$ & $12.6 \pm 0.4$ \\
Quercetin & & $4.5 \pm 0.4$ \\
\hline
\end{tabular}

\section{Acknowledgements}

This study was supported by the EU project called MUTHI (Multidisciplinary University Traditional Health Initiative, FP7-AFRICA 2010, Grant Agreement 266005) and Makerere - SIDA Phase IV project (2015/2020 Agreement).

\section{References}

[1] Khoo, H. E., Azlan, A., Tang, S. T. and Lim, S. M. (2017). Anthocyanidins and anthocyanins: colored pigments as food, pharmaceutical ingredients, and the potential health benefits. Food and Nutrition Research, 61: 361779.

[2] Li, X., Thwe, A. A., Park, C. H., Kim, S. J., Arasu, M. V., Abdullah, A. N., et al. (2017). Ethephon-induced phenylpropanoid accumulation and related gene expression in tartary buckwheat (Fagopyrum tataricum (L.) Gaertn.) hairy root. Biotechnology and Biotechnological Equipment, 31 (2): 304-311. 
[3] Zhao, D. and Tao, J. (2015). Recent advances on the development and regulation of flower color in ornamental plants. Frontiers in Plant Science, 6: 261.

[4] Tanaka, Y. and Ohmiya, A. (2008). Seeing is believing: engineering anthocyanin and carotenoid biosynthetic pathways. Current Opinion in Biotechnology, 19: 190-197.

[5] Ali, H. M., Almagribi, W. and Al-Rashidi, M. N. (2016). Antiradical and reductant activities of anthocyanidins and anthocyanins, structure-activity relationship and synthesis. Food Chemistry, 194: 1275-1282.

[6] Musilová, J., Trebichalský, P., Timoracká, M. and Bystrická, J. (2013). Cultivar as one of the factors affecting the anthocyanin content and antioxidant activity in strawberry fruits. Journal of Microbiology, Biotechnology and Food Sciences, 2 (1): $1765-1775$

[7] Scalzo, J., Stevenson, D. and Hedderley, D. (2013). Blueberry estimated harvest from seven new cultivars: fruit and anthocyanins. Food Chemistry, 139: 44-50.

[8] EFSA Panel on Food Additives and Nutrient Sources added to Food (ANS). (2013). Scientific Opinion on the re-evaluation of anthocyanins (E 163) as a food additive. EFSA Journal, 11 (4): 3145 .

[9] Simões, C., Albarello, N., de Castro, T. C. and Mansur, E. (2012). Production of anthocyanins by plant cell and tissue culture strategies, In: Orhan, I. E. (Ed.), Biotechnological production of plant secondary metabolites. Bethan Science Publishers, Dubai, p. 67-86.

[10] Passeri, V., Koes, R. and Quattrocchio, F. M. (2016). New challenges for the design of high value plant products: stabilization of anthocyanins in plant vacuoles. Frontiers in Plant Science, 7: e0136365.

[11] Appelhagen, I., Wulff-Vester, A. K., Wendell, M., Hvoslef-Eide, A., Russell, J., Oertel, A., et al. (2018). Colour bio-factories: towards scale-up production of anthocyanins in plant cell cultures. Metabolic Engineering, 48: 218-232.

[12] Fernandes, R. and Fernandes, A. (1978). Melastomataceae. In Launert, E. (Ed.), Flora Zambesiaca. Royal Botanic Gardens, Kew, 4: p. 220.

[13] Wagner, W. L., Herbst, D. R. and Sohmer, S. H. (1990). Manual of the flowering plants of Hawai. University of Hawaii Press, Bishop Museum, Honolul, 2.

[14] Kitadi, J. M., Mazasa, P. P., Tshibangu, D. S. T., Memvanga, P. B., Ngbolua, K. N., Taba, N. K., et al. (2015). Anti-sickling and antioxidant activities of anthocyanins extracts from Dissotis brazzae Cogn (Melastomataceae). Journal of Advancement in Medical and Life Sciences, 3 (4): 1-6.

[15] Moshi, M. J., Innocent, E., Masimba, P. J., Otieno, D. F., Weisheit, A., Mbabazi, P., et al. (2009). Antimicrobial and brine shrimp toxicity of some plants used in traditional medicine in Bukoba District, north-western Tanzania. Tanzania Journal of Health Research, 11 (1): 23-28.

[16] Chhabra, S. C. and Mahunnah, R. L. A. (1994). Plants used in traditional medicine by Hayas of Kagera region, Tanzania. Economic Botany, 48 (2): 121-129.

[17] Abere, T. A., Onwukaeme, D. N. and Eboka, C. J. (2009). Pharmacognostic evaluation of the leaves of Dissotis rotundifolia Triana (Melastomataceae). African Journal of
Biotechnology, 8 (1): 113-115.

[18] Aja, P. M., Alum, E. U., Ezeani, N. N., Ibiam, U. A. and Egwu, C. (2015). Comparative phytochemical evaluation of Dissotis rotundifolia root and leaf. Global Veterinaria, 14 (3): 418-424.

[19] Soyinka, J. O., Oguntade, T. O., Onawunmi, G. O., Idowu, T. O. and Ogundaini, A. O. (2008). Antioxidant and antimicrobial constituents of Dissotis erecta And Dissotis rotundifolia. Nigerian Journal of Pharmaceutical Research, 7 (1): 76-82.

[20] Andersen, Ø. M. and Fossen, Т. (2005). Characterization of anthocyanins by NMR. In: Wrolstad, R. E. (Ed.), Handbook of food analytical chemistry: pigments, colorants, flavors, texture, and bioactive food components. John Wiley and Sons Inc., Hoboken, N J, p. 47-69.

[21] Jordheim, M., Enerstvedt, K. H. and Andersen, Ø. M. (2011). Identification of cyanidin 3-O- $\beta$-(6"-(3-Hydroxy-3-methylglutaroyl)glucoside) and other anthocyanins from wild and cultivated blackberries. Journal of Agricultural and Food Chemistry, 59: 7436-7440.

[22] Adaku, C., Skaar, I., Byamukama, R., Jordheim, M. and Andersen, Ø. M. (2020). Anthocyanin profile and antioxidant property of anti-asthma flowers of Cordyline terminalis (L.) Kunth (Agavaceae). Natural Products Communication, 15 (5): $1-7$.

[23] Andersen, Ø. M. (1985). Chromatographic separation of anthocyanins in cowberry (lingonberry), Vaccinium vites-idaea L. Journal of Food Science, 50: 1230-1232.

[24] Hong, V. and Wrolstad, R. E. (1990). Use of HPLC separation/photodiode array detection for characterization of anthocyanins. Journal of Agricultural Food Chemistry, 38 (3): 708-715.

[25] Harborne, J. B. (1958). Spectral methods of characterizing anthocyanins. Biochemical Journal, 70: 0-22.

[26] Andersen, Ø. M., Aksnes, D. W., Nerdal, W. and Johansen, O. P (1991). Structure elucidation of cyanidin-3-sambubioside and assignments of the $\mathrm{H}-1$ and $\mathrm{C}-13$ NMR resonances through 2-dimensional shiftcorrelated NMR techniques. Phytochemical Analysis, 2: 175-183.

[27] Markham, K. R. and Chari, M. (1982). Carbon-13 NMR spectroscopy of flavonoids. In: Harborne, J. B. and Mabry, T. J. (Eds.), The flavonoids: advances in research. Chapman and Hall, London, p. 19-134.

[28] Reiersen, B., Kiremire, B. T., Byamukama, R. and Andersen, Ø M. (2003). Anthocyanins acylated with gallic acid from chenille plant, Acalypha hipsida. Phytochemistry, 64: 867-871.

[29] Castañeda-Ovando, A., Pacheco-Hernández, M. L., Páez-Hernández, M. E., Rodríguez, J. A. and Galán-Vidal, C. A (2009). Chemical studies of anthocyanins: a review. Food Chemistry, 113 (4): 859-871.

[30] Lowry, J. B. (1976). Anthocyanins of the Melastomataceae, Myrtaceae and some allied families. Phytochemistry, 15: 513-516.

[31] Ding, M., Feng, R., Wang, S. Y., Bowman, L., Lu, Y., Qian, Y., et al. (2006). Cyanidin-3-glucoside, a natural product derived from blackberry, exhibits chemopreventive and chemotherapeutic activity. The Journal of Biological Chemistry, 281 (25): 17359-17368. 
[32] Ghan, H. T., Kao-Jao, T. H. C. and Nakayama, T. (1977). Anthocyanin composition of taro. Journal of Food Science, 42 (1): 19-21.

[33] Bhatla, S. C. and Pant, R. C. (1977). Isolation and characterisation of anthocyanin pigment from phosphorus-deficient maize plants. Current Science, 46 (20): 700-702.

[34] Haque, M. S., Ghoshal, D. N. and Ghoshal, K. K. (1981). Anthocyanins in Salvia-their significance in species relationship and evolution. Proceedings of the Indian National Science Academy B, 47 (2): 204-209.

[35] Hanamura, T., Hagiwara, T. and Kawagishi, H. (2005). Structural and functional characterisation of polyphenols isolated from acerola (Malpighia emarginata DC.) fruit. Bioscience, Biotechnology and Biochemistry, 69 (2): 280-286.

[36] Suzuki, T., Kim, S., Islam, Z., Mohamed, S., Mukasa, Y., Takigawa, S., et al. (2007). Structural identification of anthocyanins and analysis of concentrations during growth and flowering in buckwheat (Fagopyrum esculentum Moench) petals. Journal of Agricultural and Food Chemistry, 55: 9571-9575.

[37] Srovnalova, A., Svecarova, M., Zapletalova, M. K., Anzenbacher, P., Bachleda, P., Anzenbacherova, E., et al. (2014). Effects of anthocyanidins and anthocyanins on the expression and catalytic activities of CYP2A6, CYP2B6, CYP2C9, and CYP3A4 in primary human hepatocytes and human liver microsomes. Journal of Agricultural and Food Chemistry, 62 (3): 789-97.

[38] Wang, H., Cao, G. H. and Prior, R. L. (1997). Oxygen radical absorbing capacity of anthocyanins. Journal of Agricultural and Food Chemistry, 2: 304-309.

[39] Proteggente, A. R., Pannala, A. S., Pagana, G., Van Buren, L., Wagner, E., Wiseman, S., et al. (2002). The antioxidant activity of regularly consumed fruit and vegetables reflects their phenolic and vitamin C composition. Free Radical Research, 36: $217-233$.

[40] Landrault, N., Poucheret, P., Ravel, P., Gasc, F., Cros, G. and
Teissedre, P. L. (2001). Antioxidant capacities and phenolics levels of French wines from different varieties and vintages. Journal of Agricultural and Food Chemistry, 49: 3341-3348.

[41] Seeram, N. P., Momin, R. A., Nair, M. G. and Bourquin, L. D. (2001). Cyclooxygenase inhibitory and antioxidant cyanidin glycosides in cherries and berries. Phytomedicine, 8: 362-369.

[42] Wang, H., Nair, M. G., Strasburg, G. M., Chang, Y. C., Booren, A. M., Gray, J. I., et al. (1999). Antioxidant and antiinflammatory activities of anthocyanins and their aglycon, cyanidin, from tart cherries. Journal of Natural Products, 62: 294-296.

[43] Amorini, A. M., Fazzina, G., Lazzarino, G., Tavazzi, B., Di Pierro, D., Santucci, R., et al. (2001). Activity and mechanism of the antioxidant properties of cyanidin-3-O- $\beta$-glucopyranoside. Free Radical Research, 35: 953-966.

[44] Tsuda, T., Watanabe, M., Ohshima, K., Norinobu, S., Choi, S. W., Kawakishi, S. and Osawa, T. (1994). Antioxidative activity of the anthocyanin pigments cyanidin 3-O- $\beta$-D-glucoside and cyanidin. Journal of Agricultural and Food Chemistry, 42: 2407-2410.

[45] Wang, J. and Mazza, G. (2002). Inhibitory effects of anthocyanins and other phenolic compounds on nitric oxide production in LPS/IFN-gammaactivated RAW 264.7 macrophages. Journal of Agricultural and Food Chemistry, 50: 850-857.

[46] Hu, C., Zawistowski, J. and Kitts, D. D. (2002). Phytochemical characterization and bioactivities of anthocyanins from pigmented rice. Annual Meeting and Food Expo-Anaheim, California. Session 84, Nutraceuticals \& Functional Foods.

[47] Rimpapa, Z., Toromanovic, J., Tahirovic, I., Šapčanin, A. and Sofic, E. (2007). Total content of phenols and anthocyanins in edible fruits from Bosnia. Bosnian Journal of Basic Medical Sciences, 7 (2): 119-122.

[48] Nile, S. H., Kim, D. H. and Keum, Y. (2015). Determination of Anthocyanin content and antioxidant capacity of different grape varieties. Ciencia e Tecnica Vitivinicola, 30 (2): 60-68. 